\title{
STEM COMPETENCY-BASED LEARNING FOR ENGINEERING AND DESIGN STUDENTS OF THE EDUCATIONAL MODEL TEC21
}

\author{
Carlos GONZALEZ-ALMAGUER, Mariana MAYA, Eduardo CABALLERO, Alejandro \\ ACUÑA, Claudia ZUBIETA and Consuelo YARTO \\ Tecnológico de Monterrey, Mexico
}

\begin{abstract}
This paper aims to improve the learning process of students of design and engineering on the Tecnologico de Monterrey through STEAM (Science, Technology, Engineering, Arts and Math) workshops doing emphasis on transversal learning. The new educational model at Tecnologico de Monterrey, known as Tec21 and based on competencies, has left behind the educational model based on objectives. As part of its pedagogical support, the new model has considered two kind of competencies: the transversal competencies such as collaboration, problem solution, ethical analysis, leadership, innovation \& critical thinking; and the disciplinaries competencies, for example, statistics, quality control, design of experiments, inventory control, planning, forecasting, for mention some academic areas. Competency-based learning curricular design in this educational model is necessary to transfer knowledge to students through academic activities schemed specially for it. In the Industrial Engineering and Design teamwork, we are using the play lab concepts to build academic activities with interactivity between the academic and the industry ecosystem.

To design activities that represent a challenge for the students, designer teachers are using Meccano, a metal constructive game base in STEAM education. Meccano are an approach to learning, and access points for guiding student inquiry, dialogue, and critical thinking. To make the learning process more interesting, STEAM teachers, with high academic background, transfer knowledge to the student making use of their creativity to design an academic practice both interest and attractive for students. This way students have fun time while learning real manufacturing behaviour concepts as well as forecasting, design of experiments, statistical quality control, inventory control, and supply chain.
\end{abstract}

\section{Keywords: Competency-based learning, educational innovation, Tec21, gamification}

\section{INTRODUCTION}

How does the team make interesting the study of theoretical concepts in the classroom? In the teachinglearning process, transferring knowledge to students is not easy, given that the theoretical language does not let students visualize the real working environment in a manufacturing company. That is why the initiative to form an integrative workshop in the School of Industrial Engineering on the Queretaro campus of the Tecnologico de Monterrey came about. Initially, the multidisciplinary teams who worked on it were instructors in the subjects of Experimental Design, Statistical Quality Control, and Work Design.

On par with the new educational models that have evolved at Tecnologico de Monterrey, the integrative workshop evolved, now a product was designed and then replicated in mass production during a fivehour session. The materials were not simple to handle, and the product had a considerable variance that was not easy to measure. At the beginning, the finished products were wooden music boxes whose musical mechanisms were imported.

In 2009, the Meccano models [1] were introduced, which are models made with metal and plastic parts, characterized by flexibility and repeatability in the assembly process. The systems of construction that make these have evolved in recent years, and the models are branded under the STEAM initiative, registered now as Meccano, Engineering and Robotics. Harvey [2] argues that the use of these sets helps students to have a better spatial perspective and improves their attention span and engineering thinking. 
On the other hand, Svenuis [3] highlights the benefit of Meccano when the student can break down a product and re-assemble it, making variations of the core model.

Meccano is the perfect device for the construction and articulation of different designs or products. It was created as a toy by Frank Hornby in England around 1890 and initially consisted of strips of cans assembled by screws that allowed the flexibility to make different creations, planes and cars being the most requested. In 1907, the device took the name of Meccano and began its production in different countries, including France, Spain, and the United States. Currently, Meccano is no longer just a toy, but a tool for technology and engineering.

\section{DeVelopment}

A dynamic teaching design that attracts and holds the attention of the students is a primary challenge for any instructor. With the help of Meccano as a base for generating these dynamics, the teaching teams were able to design a complete simulation of a manufacturing process where the student, through roleplay using event cards and dice, emulates the day-to-day manufacturing centre. This manufacturing process immerses the student in the analysis of internal systems, such as departments of design, procurement, product engineering, quality, logistics, testing, finance, and information systems; and external systems such as regulations, norms, sources of financing, suppliers, customers, and transport carriers, among others. Using tablets, telephones, and computers, students can monitor in real time the progress of the other departments. This immersion in semi-reality is intended to teach through the development of competencies, rather than the theoretical learning of a subject. The purpose is to get the students hooked and engaged through the game, letting them assume different roles and putting into play their creativity and resilience.

\subsection{Background}

In the semester of January to May 2009, the use of Meccano was introduced in the engineering classes, concurrent with the model, Multi-Model 2; later, the models, Design 2 and Multi-Model 10, which came with a motor, were presented in the classes of experimental design, statistical quality control, and mechatronic control.

In the mechatronics design classes, robots were created using as a base the Meccano adapted with Arduino sensors and solar cells. These creations were at the heart of the challenge-based-learning methodology that uses problem-solving and resolution of challenges to develop competencies in the students. This educational innovation was presented in Dublin, Ireland during the $15^{\text {th }}$ International Conference on Engineering and Product Design Education, EPDE 2013 [3], [4].

Subsequently, an effort was made to complement the mechatronics design classes with industrial engineering techniques, which permitted introducing experimental design and statistical quality control. Consequently, the professors created a role-playing game that simulates a manufacturing and high-tech centre in which the design of remote-controlled vehicles was achieved using Meccano parts.

The initial experiments [5] used sensors in small autonomous vehicle models, not with the use of artificial intelligence but only with the merger of industrial engineering and mechatronics techniques. The findings were presented at the $8^{\text {th }}$ Congress of Innovation and Educational Technology at the Tecnologico de Monterrey in December 2013 [6] and at the $16^{\text {th }}$ International Conference on Engineering and Product Design Education at the University of Twente in the Netherlands in September 2014 [7].

Beginning 2015, the use of the Meccano was emphasized in the areas of logistics, inventory management, and forecasting, as well as in the School of Architecture, Art and Design in the Tecnologico de Monterrey, in the subjects of Project Design and Design of Products and Services.

To illustrate the strengthening of theoretical themes in a course that employs the educational resource of a dynamic based on Meccano, we share the experience of Forecasting for Decision-making, a course that is part of the curricular grid of the students of Industrial Engineering, Marketing, Accounting, Administration and Business Creation, and International Business and Finance.

Through collaboration with the School of Architecture, Art and Design, and using the available Meccano parts, a fast-assembly car was designed in which variations could be made to generate more than one model, with repeatability, and whose bodywork could be built through 3D printers. Thus, was born the Tec 21 Sports Car Assembly.

The design of this activity emulates an Enterprise Resource Planning (ERP) system and facilitates students to design a company where the activities and departments are fully linked. For the above, if the 
flow of information is lost, they will not be able to meet the assembly demand that the customer's request through a Customer Order (CO). There are defined roles for students:

The real dynamics of an assembly plant are simulated: the customer, by agreement with Marketing, generates a purchase order, which advances to the buyers of materials. They should consult the productivity index, because, if the purchase order is for 40 cars, it is a mistake to buy the parts kits for that amount of product if the productivity index suggests buying more to counteract design and quality problems that might arise.

Each family of parts has its historical data and its manufacturing and delivery times, some shorter, others longer, and the assembly begins when all the parts kits are stocked. This is where it is crucial to calculate forecasts to anticipate the purchase order placed by the customer and place orders for the parts to suppliers so that the parts arrive in time to reduce the delivery time of the product.

Having the purchase order simultaneously generates the indices of productivity for each workstation using a spinning top with six faces. On its faces, the top has indices of 80, 85, 90, 95, 99 and 100\%. Multiplying the indices of each station yields the final index for the assembly plant. Each of the materials supply plants has its own productivity value. In professional life, these kinds of dynamics happen, and if the student can identify the importance of generating the forecast and adjust it according to productivity, he or she will take a giant step towards the acquiring of graduate skills.

There is a supply chain of materials and its logistics to consider. The parts come from Asia, Europe, the United States, and Mexico, and one must select the appropriate means of transport based on cost and time. For example, if the raw material is made in Hungary, it must be transported to the port either by train or truck, make the customs declaration and embark. In real life, it is probable that the boarding has an error in the documentation, and this is simulated using a spinning top, which has one face of error and five of success. (Therefore, there is one chance in six of an error.) When the spinning top indicates an error, the delay time is determined by the roll of a die, so that the delay can be one to six days.

Other factors that are not considered in the generation of a forecast in books or theory are the accident claims. Historically, there is an accident and theft index or factor depending on the mode of transport; in fact, there is even a factor for damage to the raw material, because if the appropriate packaging is not used, when transporting equipment by sea, it can be damaged by the effects of saltwater. In the simulation, these factors are also determined with spinning tops and dice.

The systemic approach of the game allows students to monitor and observe at the current moment what is happening in each department through social networks, in this case, Twitter and Facebook. Concurrent thinking generates a collaborative work model in parallel, reducing sequential work tasks to their minimal expression, while prospective thinking helps the students to move assembly events forward.

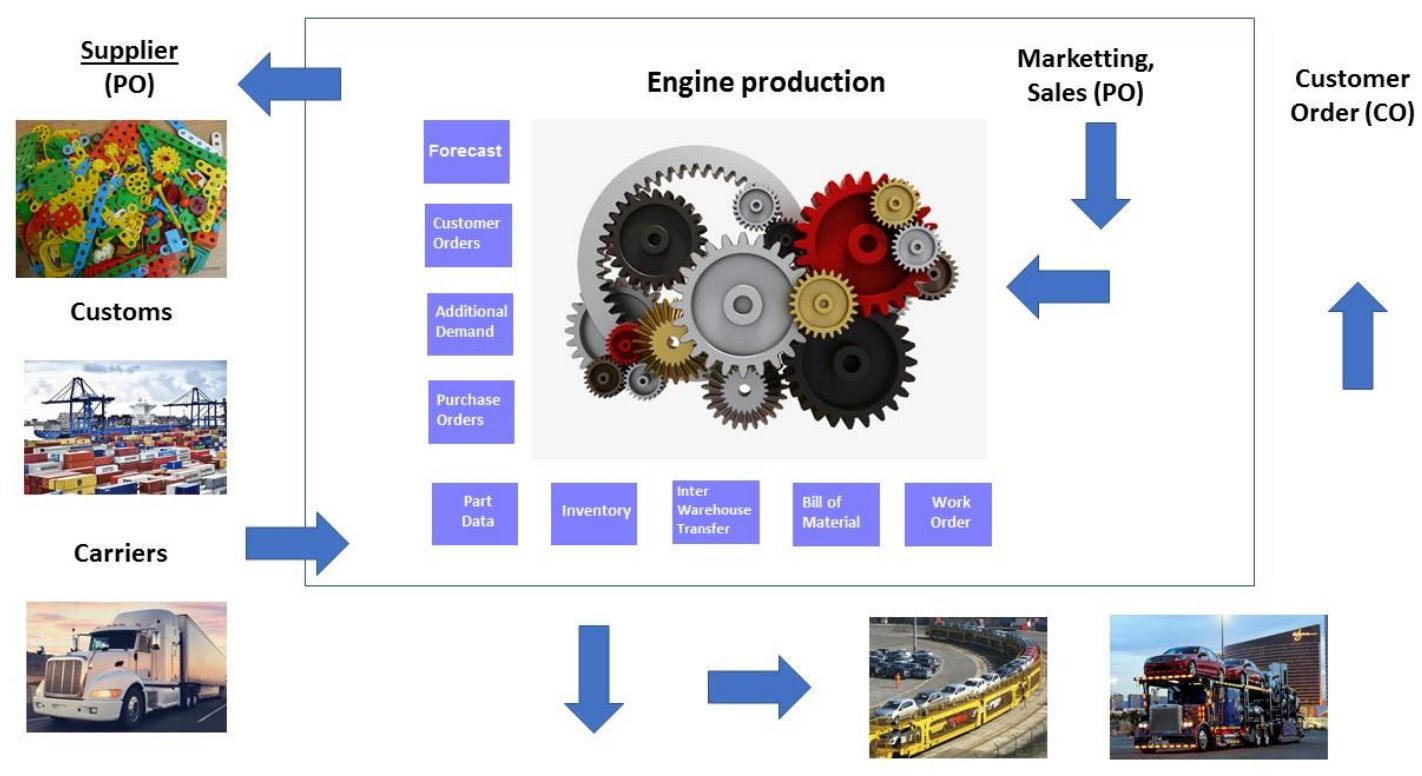

Figure 1. Meccano workshop schedule 
At the end of the dynamic, a compilation of the events is made, and all the incidence sheets are collected for the elaboration of statistics and the final report, in which the students reflect upon the application of their knowledge, build a business model, and elaborate a methodology to solve the forecasting problem.

\subsection{Learning experience}

Critical thinking and information analysis are some of the competencies that engineering students must develop, together with the knowledge and management of statistical concepts. These include the mean, variance, standard distribution, their application in a times series forecasting and models based on the variability, trend, and seasonality of data, basic concepts of quality control and productivity, concurrent engineering, and systemic thinking.

All these skills and knowledge can be addressed inside the classroom through gamification, and, in the specific case that is presented, the Meccano was used to engage the students to solve a real situation with the help of a game.

The technical knowledge of the creative phase is necessary to adapt the dynamics to the theoretical concepts that are required to be emphasized, as well as to transform the theoretical concepts into table games and roleplay. The knowledge of the Meccano models is also essential, even to know where a design can be done and what parts can be machined in the workshops and laboratories that are available, so as not to limit the creativity of the students. The models used in the early stages are found in Figure 2 .
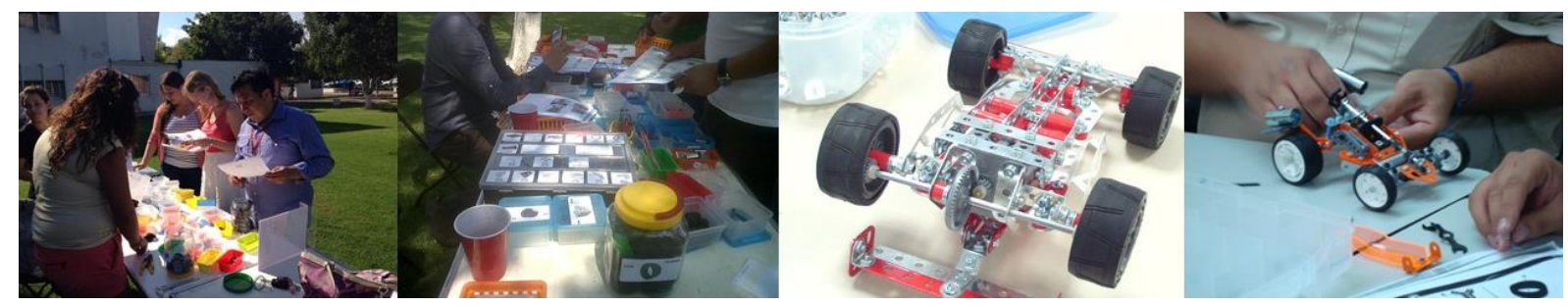

Figure 2. Meccano models used in the first stages of the innovation

The role of gamification in the field of education has no other purpose than to bring motivation to the teaching-learning process by incorporating elements and techniques of play. A process used well delivers multiple advantages to enrich the relationship between teachers and students to improve the climate in the classroom. The gamification allows carrying the different mechanics and techniques in the games to contexts that have nothing to do with play, to try to solve a real problem.

In the multidisciplinary model, students of industrial engineering, mechatronic and mechanical design an airplane with the Meccano (using solar panels and Arduinos code program), and the design students build the airplane fuselage design using 3D printers. Applying play lab concepts, the benefits to the students are:

- Apply existing knowledge to generate new ideas, products, or processes.

- Create original works as a means of personal or group expression.

- Use models and simulation to explore complex systems and issues.

- Plan and manage activities to develop a solution or complete a project.

- Use multiple processes and diverse perspectives to explore alternative solutions.

- Transfer current knowledge to learning of new technologies

\subsection{Evaluation of results}

For the purposes of evaluating the implementation of Meccano, a closed survey was given to alumni who are working in the industry, specifically in the area of manufacturing, to assess the impact of the use of Meccano in their process of adaptation to work. The use of Group Interview was the best decision for the inference of the results, in this interview technique, questions are asked to a group of respondents selected for a specific purpose, in this case measure the effectivity of the workshop for our students [9]. In a sample of 55 professionals from a population of more than 485 alumni who work in the manufacturing industry and took this workshop in the areas of experimental design, statistical quality control, project management and evaluation, mechatronic design, and forecasts for decision making, the results are as follows: $93.3 \%$ consider that the dynamics allowed them to have a better vision on the systemic aspect of the industry; $54 \%$ consider that it improved their theoretical knowledge upon bringing 
it into practice; $25 \%$ consider that it significantly improved their knowledge, and $14 \%$ believe that there was no meaningful learning.

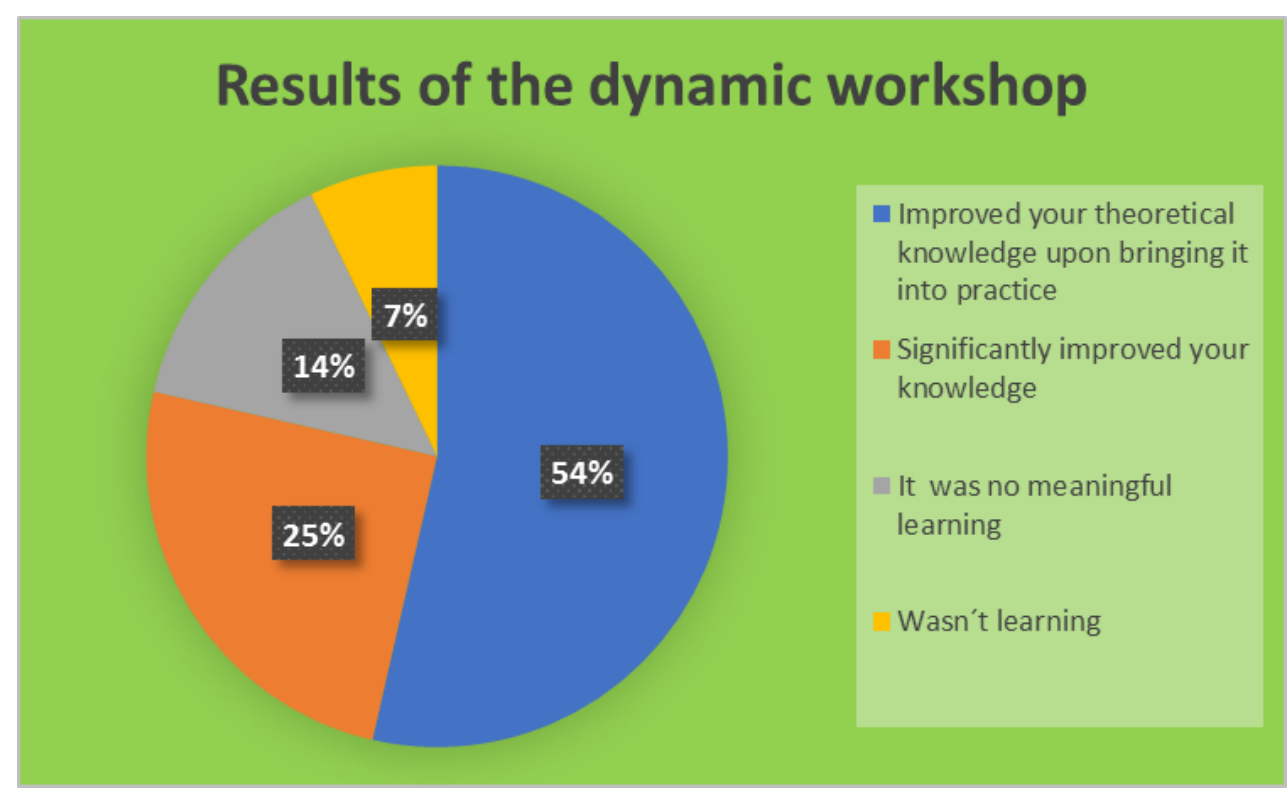

Figure 3. Results of the dynamic workshop

For the engineering students, the acquired knowledge was good, while the bachelor's degree students indicated that their knowledge was significant. The latter could be explained on the basis that these students had no previous exposure to a real manufacturing environment, and the course helped them to have a systemic vision of what happens in a company.

The testimonial evidence of the alumni affirms that the course dynamics allowed them to have better work performance, compared with those alumni who did not take on a similar professional practice.

\section{CONCLUSIONS}

To overcome paradigms between professors and students is gratifying. Through a didactic resource like gamification [8], the students can reaffirm their knowledge through well designed and structured games, where they must apply the knowledge received in class to win. Acquiring and perfecting professional skills through games as old and simple as Meccano develops in the students a sense of professional security that helps them to face real-world challenges after graduation.

Depending on the course taught, the practical activity can become as complex as in the case of designing robots that function through solar energy with the use of motors, servomotors, and motion and sound sensors, or as simple as the assembly of a race car.

Learning while having fun leaves the student with excellent experiences. It allows him or her to have more resilience and learn more quickly from failures. It arouses a sense of curiosity, facilitates decisionmaking about the tasks that must be done, and promotes teamwork. On the other hand, the professor faces intense challenges to perfect and design best practices based on new models of Meccano.

\section{ACKNOWLEDGMENTS}

The authors would like to acknowledge the financial and the technical support of Writing Lab, and Tecnologico de Monterrey, Mexico, in the production of this work.

\section{REFERENCES}

[1] Meccano, Marriot, R., Shire Publications, 2012, ISBN 13: 9780747810568

[2] Rosaspage. History of the Meccano. Retrieved from: http://www.rosaspage.com/art/emeccano.html

[3] The $15^{\text {th }}$ International Conference on Engineering \& Product Design Education. Design Education Growing our Future. González, C.A., Manríquez, J., Trelles, S., Reyes, L.D., G. Neria, X., Acevedo, A., Ávila, J.M. Lloveras, J. Rioja, O. September 5 and 6, 2013 
[4] The $15^{\text {th }}$ International Conference on Engineering \& Product Design Education. Mechatronic Design for Students, Model Based on Industrial Engineering Techniques. Dublin, Ireland. September 5 and 6, 2013

[5] The $16^{\text {th }}$ International Conference on Engineering \& Product Design Education. Design Education \& Human Technology Relations. González. C.A, Arriaga, F., Manríquez, J., Acuña, A., Huerta, R., González, G. Lloveras, J. September 2014

[6] $8^{\text {th }}$ Congress of Innovation and Educational Technology. González, C.A., Manríquez, J. Elaboration of mechatronics projects through a model based on techniques of industrial engineering. Tecnologico de Monterrey, Monterrey, N.L. México. December 11 to 13, 2013

[7] Teaching Ethics in Engineering and Design. The Necessity of Concurrent Engineering. Twente University, Netherlands, September 4 and 5, 2014.

[8] Fernando Rodríguez y Raúl Santiago. (2015). Gamification. How to motivate your student and improve the climate in the classroom. Spain: Ocean.

[9] Atatürk Üniversitesi Sosyal Bilimler Enstitüsü Dergisi 200913 (1): 201-216 Questionnaires and Interviews in Educational Research Hüseyin, Hasan. 